\title{
ACHIEVING SUSTAINABILITY IN THE WATER SECTOR THROUGH PROJECT MANAGEMENT IN BULGARIA Zornitsa Stoyanova ${ }^{1}$, Hristina Harizanova-Bartos ${ }^{2}$, Ivelina Petkova ${ }^{3}$
}

\begin{abstract}
Issues related to the water sector and the achievement of an integrated sustainable management of water resources are of interest to many researchers and practitioners. The need for effective solutions for water resources requires the use of project management to achieve sustainability in the sector. The aim of the paper is to assess the possibilities for achieving sustainability through project management in the water sector and on this basis to propose recommendations for sustainable and integrated water resources management.

The paper presents a literature review of achieving sustainability in the water sector. The analytical part of the article includes an assessment of the respondents' opinion for achieving sustainability in the water sector based on structured interviews. On this basis proposals for achieving sustainable and integrated water resource management through projects are made. The results in the paper are related to the determination of the factors for achieving sustainability in the water sector and the benefits from the water projects. On this basis are outlined opportunities for overcoming the constrains in front of the water projects. The paper presents part of the university scientific research project NID NI 1-7/2015 "Project management of sustainable development in water sector".
\end{abstract}

JEL Classification Numbers: O22, Q01, Q25; DOI: http://dx.doi.org/10.12955/cbup.v6.1200

Keywords: water, project, sustainability, management, integration

\section{Introduction}

Project management and sustainable development are scientific areas that are developing dynamically and their combination requires the outline of a clear systematic concept. New issues related to the water sector and the achievement of integrated sustainable water management requires the use of project management to achieve sustainability in the sector. This topic is in the interest of researchers and practitioners and some of the reasons are related to searching for effective solutions for project management to achieve a sustainable water sector, changes in the national and European policies and regulations for water etc.

Integrated management of the use and conservation of natural resources takes place in the water sector through the development and implementation of projects. Project management creates prerequisites for flexibility and opportunities to provide more competitive quality services, sustainable innovations, ecosystems protection, and to ensure sustainable use of water resources. Water is a renewable resource and therefore the quality of water needs to be maintained. At the same time, quality is deteriorated in many regions. In this respect, water management and the financing of water projects could lead to sustainability in the water sector and aquatic ecosystems.

In the context of the Bulgarian reality, the achievement of sustainability in the water sector and the management and financing of water projects face a number of challenges and constrains. For this reason, it is of significant importance to determine the factors for achieving sustainability in the water sector and the opportunities for overcoming the barriers in front of water projects.

The aim of the paper is to assess the possibilities for achieving sustainability through project management in the water sector and on this basis to make recommendations for sustainable and integrated water resource management.

\section{Literature review of achieving sustainability in water sector}

A prerequisite for achieving a sustainable water sector through projects includes the implementation of integrated water resource management and the implementation of the concept of sustainability in project management (Figure 1).

According to the survey (OECD, 2014), integrated water resource management is related to the implementation of the following principles: basin management approach, cross-sectoral and vertical water management coordination, transparency and public participation, ensuring sustainable use of water resources, and protection of ecosystems, financial stability of water management. Basin-level water management involves complex interactions between social, economic and environmental

\footnotetext{
${ }^{1}$ Business faculty, UNWE, zstoyanova@unwe.bg

${ }^{2}$ Business faculty, UNWE, h.harizanova@gmail.com

${ }^{3}$ Finance and Accountancy faculty, UNWE, ivapetkov@abv.bg
} 
aspects. In this respect, EU Directive 2007/60 (EU, 2007) on the assessment and management of flood risks states that sustainable water management requires consideration of the complexity of the interaction between the three aspects, including their impact on management decisions to achieve sustainability in general. Transparency and public participation play a role in achieving integrated water management, as efficient allocation requires water to be distributed amongst many legally competing users for different uses (Tietenberg \& Lynne, 2012). Grambow (2013) considers that integrated water resource management deals with natural water resource and related ecosystems. The main goal is a long-term water supply and maintaining a viable environment, taking into account social and economic conditions. Water management is linked to the need of a comprehensive and long-term assessment of the decisions and their impacts on the ecosystem as well as to the continuous improvement of policies and management practices (Pahl-Wostl, 2007). According to the OECD study (2012), the financial stability of water management can be achieved through the application of the following principles: polluter and beneficiary pay, equity and coordination between water policies.

According to Mitev (2011) integrated water resource management should be based on a new conceptual framework that takes into account the links between water resource management and water industries. In addition integrated water management requires all relevant key factors be taken under consideration in the decision-making process (Bouwer, 2000). An application holistic approach is used for the methodology. This approach is linked to both water supply management, as well as to demand, quality, storage and pollution of different types of water resources. In a subsequent study, the author Bouwer (2003) states that the basic prerequisites for sustainable water sector development and for the prevention of natural disasters, the principles of integrated water management and international cooperation are simultaneously applied.

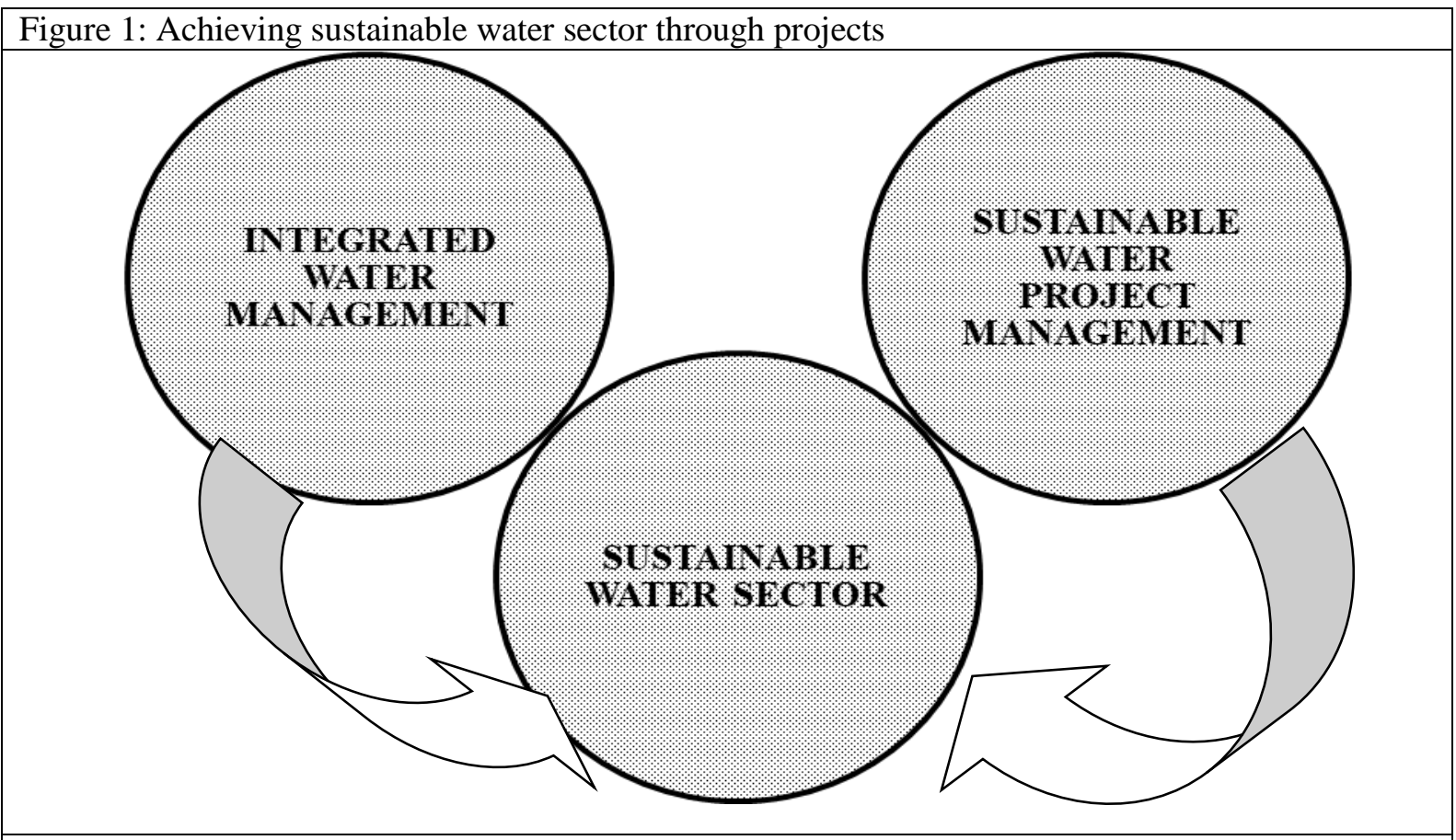

\section{Source: Authors}

Achieving sustainability in the water sector and the implementation of integrated water resource management also requires the incorporation of sustainable development principles into project management (Stoyanova \& Petkova, 2017). According to Daneshpour (2015), sustainable development is integrated into the different levels of society, and projects have a large impact as instruments for achieving change. One of the major advantages for integrating sustainable development into project management includes the social and environmental dimensions of sustainable development in project management. Some researchers are directed to measuring the influence of principles of sustainability and their impacts on the social and organizational spheres of the project (Silvius et al., 2012). Integration between these areas will also affect the number of stakeholders, since 
the inclusion of the short-term and the long-term aspect and the regional rather than the global level will lead to an increase in the number of stakeholders.

According Griffiths (2007) integrating sustainability into project management ensures that the project includes environmental sustainability practices at every stage of the project process - design, construction etc. This takes into account the social and economic aspects of project implementation and provides the management with tools for stimulation and remuneration.

Some authors (Griffiths, 2007; Moeller \& Tayler, 2010; Ilies et al., 2010) argue that integrating sustainability into project management contributes to creating positive effects for the population. Part of the projects contribute to the sustainability of the external environment and create prerequisites for economic and social prosperity in the territory in which the projects physically occurs.

On the basis of author's opinions could be made the conclusion that achieving sustainability in the water sector through projects requires taking into account a specific approach: 1) the specifics of the water sector - technological, technical, length, investment, information and other sector requirements; 2) comprehensive legislation in water sector - laws and regulations on environmental protection, water, health, safety, 3) principles for achieving sustainable development and implementation of environmental practices.

\section{Methodological framework}

The methodological framework of the paper includes: 1) a literature review of achieving sustainability in the water sector; 2) an assessment of the respondents' opinion for achieving sustainability in the water sector 3) proposals for achieving sustainable and integrated water resource management through projects.

The results in the paper are part of the university scientific research project "Project management of sustainable development in water sector" (Stoyanova, 2015).

For the purposes of the study a survey was carried out among beneficiaries under OPE 2007-2013, axis Water. The survey was conducted in the period of July-September 2016. The selected method was a structured interview. The criteria for selection of the respondents are presented in Figure 2.

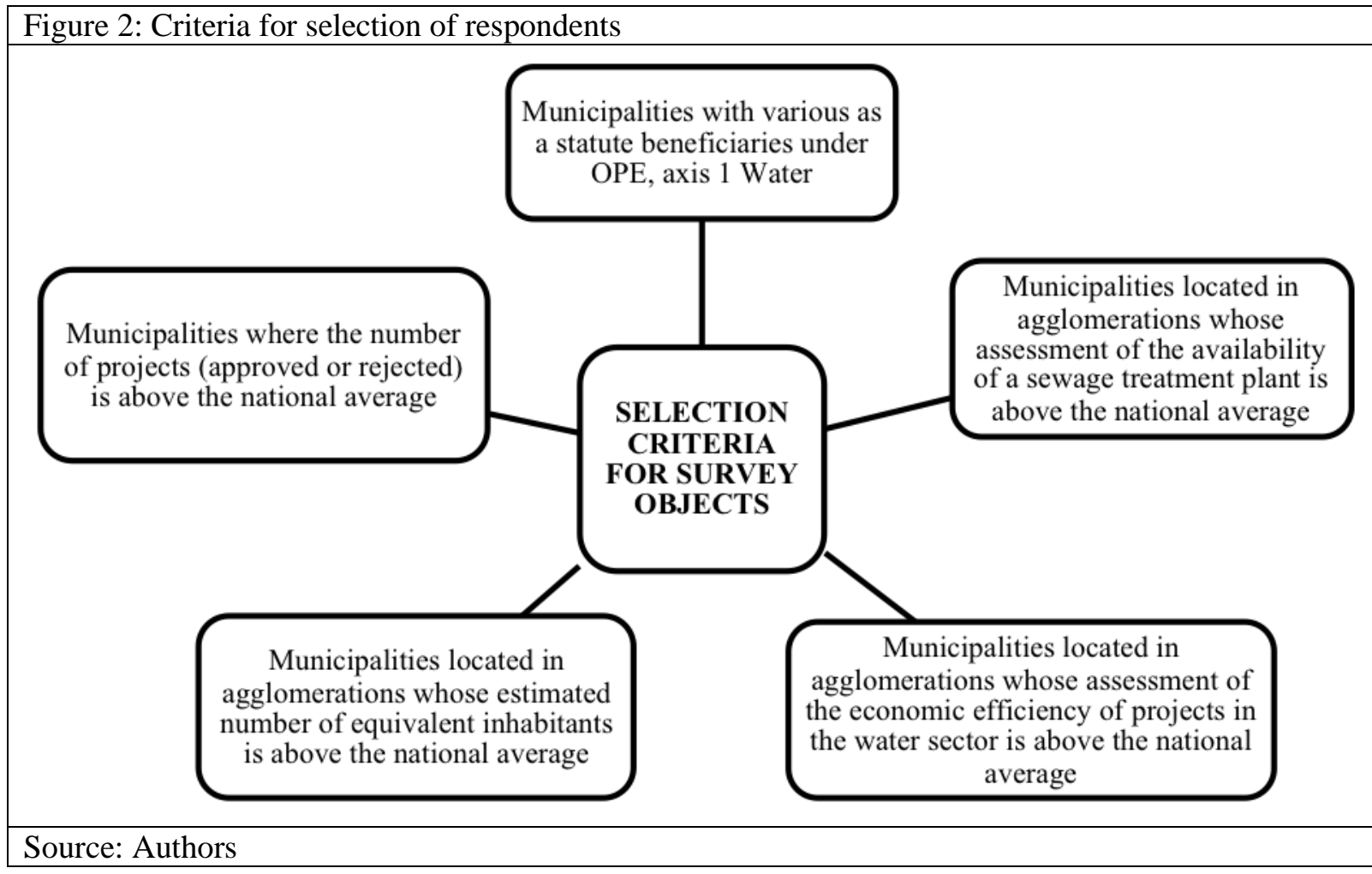

A necessary condition of participation in the survey was that each of the studied municipalities had included agglomerations to meet the minimum two criteria according to the used methodology (of 5). The number of municipalities is 19 and $63 \%$ of them meet the requirements, fulfilling more than two 
criteria. The value of the different criteria is calculated according the data from the methodology for selection of projects under OPE 2007-2013, axis 1 Water (MOEW, 2009).

As a result of the implementation of the described approach, a sample of 19 municipalities was formed which are located in 13 districts. They represent around $10 \%$ of the municipalities applying under OPE 2007-2013, Axis 1 Water and 21\% of the total projects proposals (approved or rejected).

\section{Assessment of achieving sustainability in water sector - results and discussion}

According to the conducted survey, and the gathered and analyzed information, one of the most important factors for achieving sustainability in the water sector is water policy and state institutions. $75 \%$ of the respondents consider that water policies are a very important factor, $15 \%$ are rather important, and $65 \%$ consider that state institutions are definitely an important factor and $30 \%$ consider that they are a rather important factor (Figure 3). Factors such as access to capital markets, the presence of associations and organizations with interests in the water sector are also highly evaluated (around 75\% of the answers are positive). Opinions on the importance of climate factors to achieve sustainability in the water sector differ. $30 \%$ of the respondents consider that climate factors are rather important factor, $10 \%$ that they are definitely important factor. The other $30 \%$ of the respondents have an opposite opinion. 5\% of them evaluate climate factors as not important, and $25 \%$ that they are a rather not important. About $20 \%$ of respondents have no opinion on the various factors.

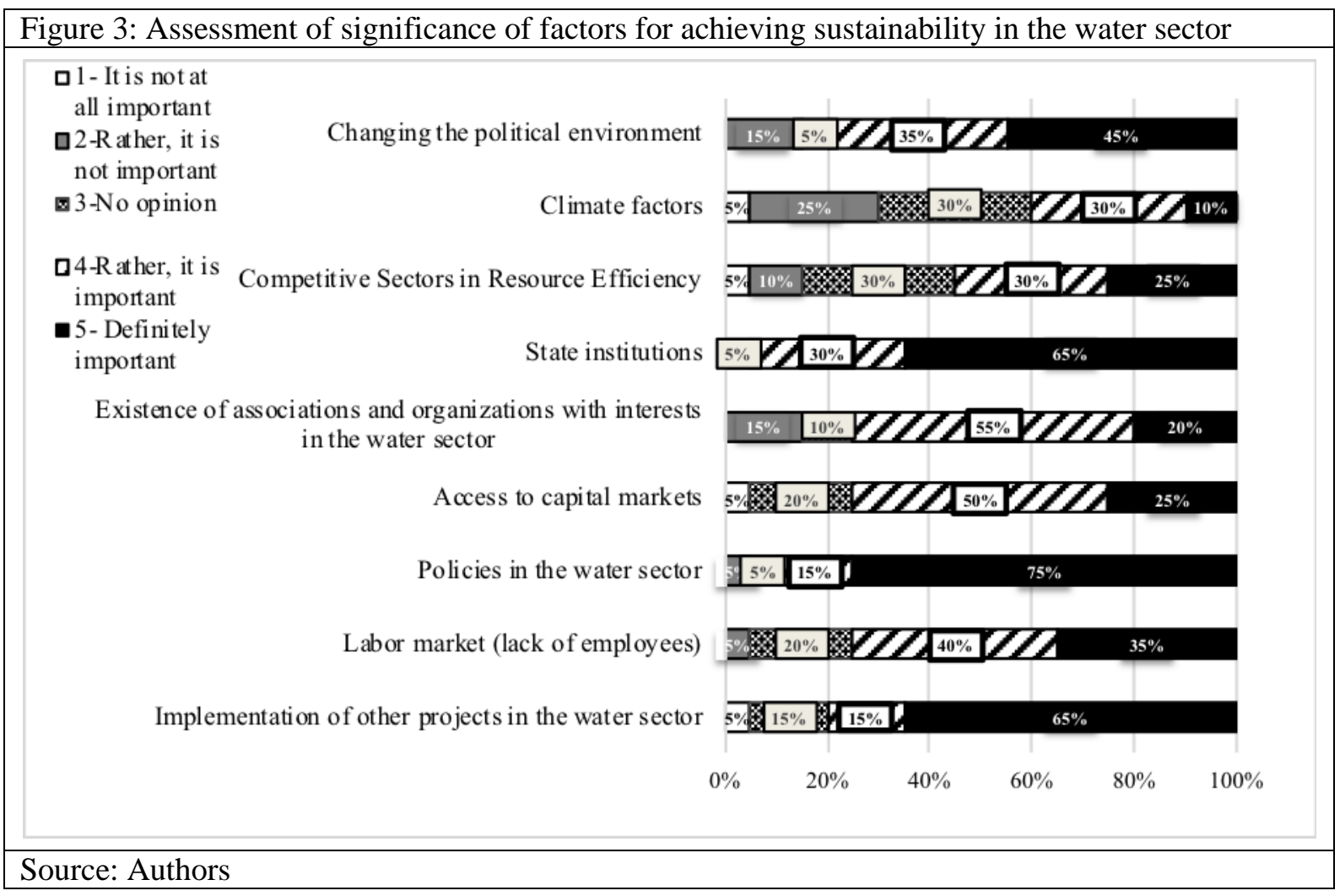

In general the beneficiaries are agree almost in terms of the statements for achieving sustainability through project management. Most of the proposed statements for evaluation collected more than $50 \%$ positive approval with the answer absolutely agree (Figure 4). 1) $75 \%$ of the respondents absolutely agreed with the statement "Financing through projects in the water sector has positive economic, social and environmental implications" and $20 \%$ agreed to some extent with this statement. 2) $60 \%$ of the beneficiaries absolutely agree that project management is a prerequisite for implementing innovative solutions and greening the water sector and $20 \%$ of them agree to some extent. 3) $60 \%$ of the respondents believe that project management contributes to reducing the risk of floods and other natural disasters, 5\% do not agree with the above mentioned three statements, and $11 \%$ of them absolutely disagree with the statement that improvement of project management lead to achievement of sustainable water sector. 


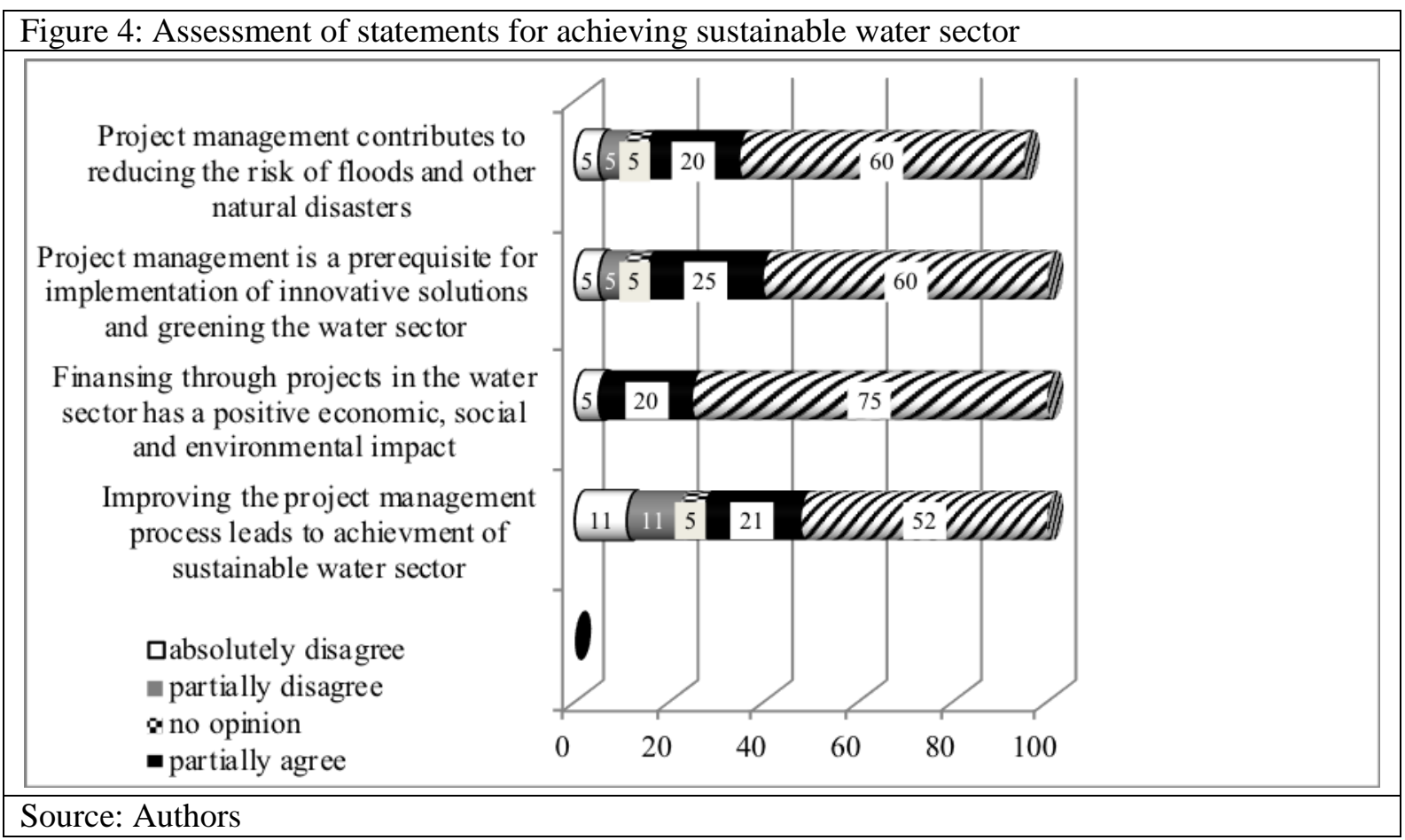

In general respondents evaluated highly the various possible benefits from the realized projects for achieving sustainability in the water sector (Figure 5). More than half of them consider that improvement and development of the infrastructure for drinking $(58 \%)$ and waste $(57 \%)$ waters, preservation and improvement of the ecological status of the water in the municipality $(55 \%)$ have high benefits. Only 5\% of respondents shared the view that increasing the capacity to respond to floods, the improvement of air quality, reducing costs in the water sector have no benefits for achieving sustainability.

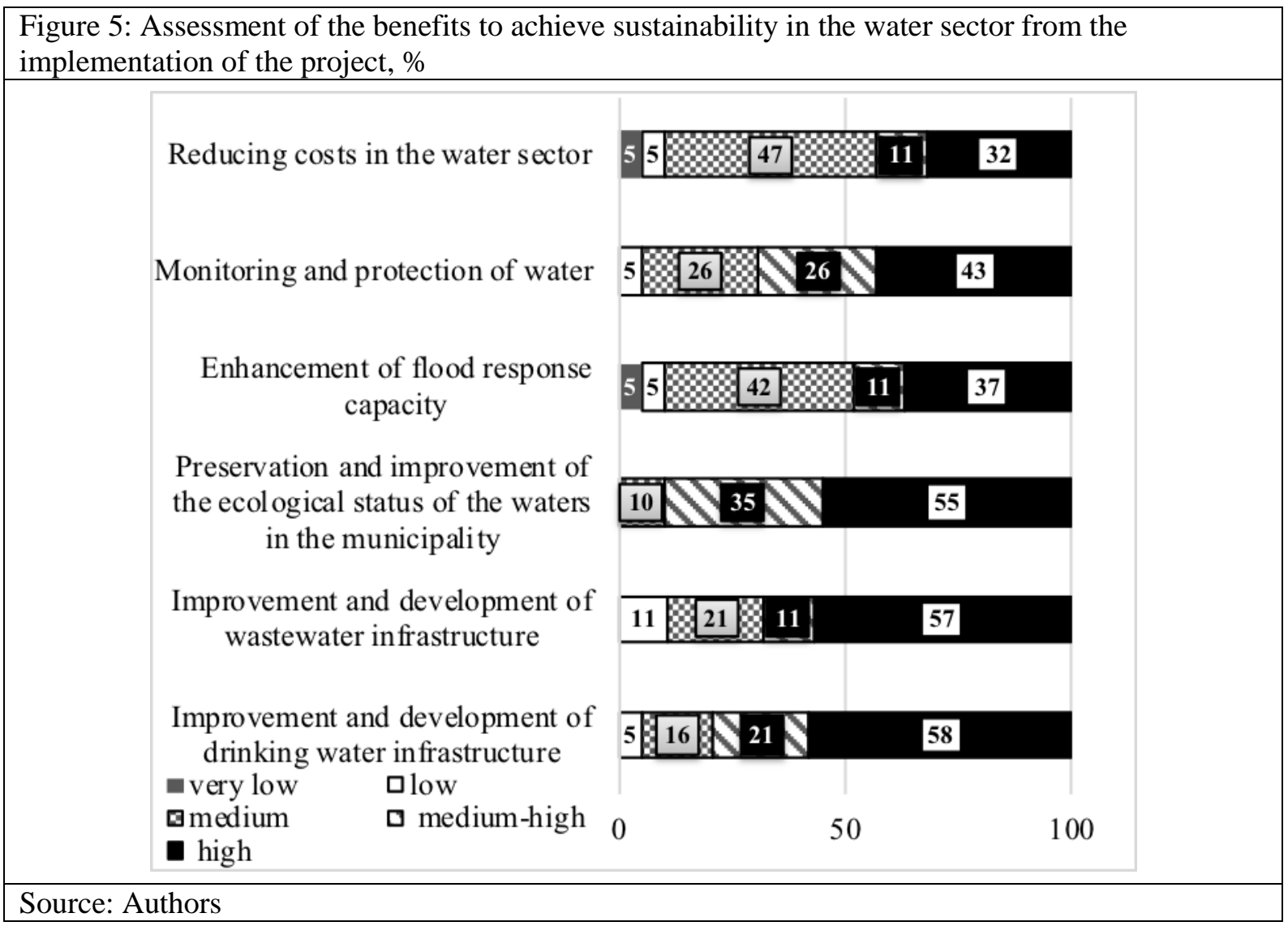




\section{Conclusions and recommendations for achieving a sustainable water sector through integrated water and project management}

Political factors such as policies in the water sector, government institutions, and changes in the political environment are some of the factors that are highly evaluated in terms of their importance. Most of the respondents consider that: 1) financing through projects in the water sector has positive economic, social and environmental implications; 2) project management is a prerequisite for implementing innovative solutions and greening the water sector; 3) project management contributes to reducing the risk of floods and other natural disasters; 4) improvement of project management lead to the achievement of a sustainable water sector. Benefits from the realized projects for achieving sustainability in the water sector are related to the improvement and development the infrastructure for drinking and waste waters, the preservation and improvement of the ecological status of the water in the municipality, and the monitoring and protection of water.

The interviewed beneficiaries consider integrated water resource management and sustainable management of water projects as of significant importance for achieving a sustainable water sector. In this respect, special attention should be paid to the opportunities and constrains to achieve a base management for all types of water resources identifying: 1) all possible users of water 2) all possible uses of water. Cross sectorial and vertical coordination of water management is needed. Important prerequisites for the development of effective vertical and horizontal cooperation are coordinated between the various stakeholders and joint planning with the support of the institutions and the availability of institutional stability. The benefits of water infrastructure will be shared through good cooperation and the negative environmental impacts in the water sector will be mitigated.

The presence of associations and organizations with interests in the water sector is highly evaluated from the beneficiaries. In this respect transparency and public participation are essential to achieve sustainability of water management as a large number of institutions, sectors and individual consumers are water users and are stakeholders in water management. In this context it is important to extend public participation in water management and water projects. It is necessary to apply sustainable practices for long-term water use that require participation in planning, decision-making, implementation and monitoring processes. Transparency and publicity can be achieved by involving all stakeholders in some of the phases of water management and financing. It is necessary in the initial preparation of a water project that all stakeholders provide the necessary information to achieve sustainability in the design and the implementation of the project in order to prevent negative consequences for the environment.

Achieving sustainability in the water sector and the water ecosystems are considered by the respondents as a key objective in water management. Integrated water resource management should lead to the preservation of ecosystems. This can be done by including sustainability criteria from the design stage of the project and to be monitored during its implementation. Sustainability criteria can be environmental management practices, energy efficiency, waste management, biodiversity conservation, best practices for land use, sustainable practices for green public procurement, staff management and development, etc.

In respect to the political factors evaluated from the respondents as the most significant there is a need for stability in the institutions responsible for water resources and the implementation of water policy. Achieving a sustainable water sector requires funding for water management, water infrastructure and water services. At the same time it is necessary to stimulate and build up public-private partnerships that create a working mechanism for financing and managing infrastructure projects in the water sector. In this regard communication activities such as the establishment of national and international networks and various partnerships between organizations of different types could be realized. The implementation of projects in the water sector should be implemented through inter-state and crossborder cooperation for the joint management, use and conservation of transnational water resources.

Applying an integrated approach to water management and incorporating the concept of sustainability into project management leads to sustainable and cost-effective solutions for the water sector. Sustainable management of water projects maximizes the ecological potential of water resources and has a positive impact on the quality of supply, storage and protection of water resources. 


\section{References}

Bouwer, H. (2000). Integrated water management: emerging issues and challenges. Agricultural Water Management, Vol. 45 (3), 217-228.

Bouwer, H. (2003). Environment Integrated water management for the 21st century:Problems and Solutions. Food, Agriculture \& Environment, 1(1), 118-127.

Daneshpour, H. (2015). Integrating Sustainability into Management of Project. International Journal of Environmental Science and Development, 6(4).

EU. (2007, October 23). http://eur-lex.europa.eu/legal-content/EN/TXT/?uri=celex:32007L0060. Retrieved February 13, 2018, from http://eur-lex.europa.eu.

Grambow, M. (2013). Nahhaltige Waserbewirtschaftung. [Sustainable water management ].Wiesbaden: Springer Vieweg.

Griffiths, K. (2007). Project sustainability management in infrastructure projects. 2nd International Conference on Sustainability Engineering and Science, (pp. 1-14). Auckland.

Ilies, L., Crisan, E., \& Muresan, I. N. (2010). Best Practices in Project Management. Review of International Comparative Management, 11(1), 43-51.

Mitev, T. (2011). Ustořchivo izpolzvane na vodnite resursi na Republika Makedoniya [Sustainable use of the water resources of the republic of Macedonia]. Sofia: SU "Saint Climent Ohridski".

Moeller, J., Tayler, T., \& Goldstein, B. (2010). Sustainable Water Resource Management. California: Electric Power Institute Research.

MOEW. (2009, November 1). Podkhod i metodologiya za podbor na proektite po prioritetna os 1 na Operativna programa okolna sreda 2007-2013 [Approach and methodology for selection of projects under priority axis 1 of OPE 2007-2013].Sofia, Sofia, Bulgaria: MOEW.

OECD. (2012). A framework for Financing Water resource management. Paris: OECD publishing.

OECD. (2014). Integrated Water Resources Management in Eastern Europe, the Caucasus and Central Asia. Geneva: OECD.

Pahl-Wostl, C. (2007). Transitions towards adaptive management of water facing climate and global change. Water Resources Management, Volume 21 (Issue), pp 49-62.

Silvius, G., S. R., Planko, J. v., \& Köhler, A. (2012). Sustainability in Project. Abingdon: Ashgate publishing.

Stoyanova, Z., Dojtchinova, J., Petkova, I., Atanasov, B., Todorova, K., \& Kynchev, I. (2015). Proektno upravlenie na ustoichivoto razvitie na vodniya sektor [Project management of sustainable development of water sector]. UNWE. Sofia: UNWE.

Stoyanova Z.,Petkova I., (2017), Project financing of the water sector in Bulgaria, Trakia Journal of Sciences, Vol. 15, Suppl. 1, pp 93-98, 2017, Trakia university.

Tietenberg, T., \& Lynne, L. ( 2012). Environmental \& natural resource economics. New Jersey: Pearson Education, Inc. 